\title{
TOLL-LIKE RECEPTOR 2/6-DEPENDENT STIMULATION OF MESENCHYMAL STEM CELLS PROMOTES ANGIOGENESIS BY PARACRINE FACTORS
}

\author{
K. Grote ${ }^{1, \S}$, M. Petri ${ }^{2, \S}$, C. Liu ${ }^{2}$, P. Jehn ${ }^{3}$, S. Spalthoff ${ }^{3}$, H. Kokemüller ${ }^{3}$, M. Luchtefeld ${ }^{1}$, T. Tschernig ${ }^{4}$, C. Krettek ${ }^{2}$,
} C. Haasper ${ }^{2}$, and M. Jagodzinski²

\author{
${ }^{1}$ Clinic for Cardiology and Angiology, Hannover Medical School, Hannover, Germany \\ ${ }^{2}$ Trauma Department, Hannover Medical School, Hannover, Germany \\ ${ }^{3}$ Department of Oral and Maxillofacial Surgery, Hannover Medical School, Hannover, Germany \\ ${ }^{4}$ Institute of Anatomy and Cell Biology, Medical Faculty of the Saarland University, Homburg/Saar, Germany
}

${ }^{\S} \mathrm{K}$. Grote and M. Petri contributed equally to this study

\begin{abstract}
Reconstruction of critical size bone defects represents a major challenge in orthopaedic surgery. Insufficient angiogenesis is a limiting factor for engraftment of largescale tissue transplants. Transplantation or stimulation of local mesenchymal stem cells (MSCs) represents a potential solution to enhance angiogenesis. We recently identified angiogenic properties for the Toll-like receptor (TLR) 2/6 agonist MALP-2 and now investigated if MALP-2 could be used to stimulate MSCs in order to promote angiogenesis in vitro and in vivo.

Human MSCs from the bone marrow of healthy subjects were isolated, cultured and expanded in vitro and were shown to be positive for mesenchymal stem cells markers as well as for the MALP-2 receptors TLR2 and TLR6. MALP-2 directly enhanced migration but not proliferation of human MSCs. Conditioned medium from MALP-2 stimulated MSCs significantly increased proliferation, migration and tube formation of endothelial cells. Analysis of the conditioned medium from MSCs revealed that MALP-2 stimulation enhanced the secretion of several chemokines and growth factors including vascular endothelial growth factors (VEGF) and granulocytemacrophage colony-stimulating factor (GM-CSF). Finally, we studied MALP-2 effects on MSCs in a sheep model of tissue engineering in vivo. Therefore, MSCs were isolated from the iliac crest of black head sheep and co-cultivated with MALP-2 ex vivo. Implantation of autologous MSCs within a scaffold cylinder into the M. latissimus dorsi significantly enhanced vessel density of these constructs after 6 months.

We here present the first evidence that TLR2/6dependent stimulation of MSCs promotes angiogenesis in vitro and in vivo offering a novel strategy for therapeutic angiogenesis, e.g., for tissue engineering of bone.
\end{abstract}

Keywords: Tissue engineering; angiogenesis; Toll-like receptors; mesenchymal stem cells; growth factors.

*Address for correspondence:

Maximilian Petri

Trauma Department

Hannover Medical School

Carl-Neuberg-Str. 1

30625 Hannover, Germany

Telephone Number: +495115322050

FAX Number: +495115325877

E-mail: petri.maximilian@mh-hannover.de

\section{Introduction}

Regeneration of critical size bone defects remains a major problem in orthopaedic surgery. Bone is a highly vascularised tissue reliant on the close spatial and temporal connection between blood vessels and bone cells to maintain skeletal integrity. In this regard, insufficient angiogenesis is a limiting factor for larger scale tissue engineering of bone (Kanczler and Oreffo, 2008). Novel methods - e.g., cell based therapies - seem to be promising approaches in regenerative medicine. In particular by using mesenchymal stem cells (MSCs), good results have been reported for bone tissue engineering in a number of clinical studies (Gómez-Barrena et al., 2011).

Toll-like receptors (TLRs) are initially discovered as receptors of the innate immune system recognising pathogen-associated molecular patterns (PAMPs) from invading pathogens in order to organise the body's immune defence via the activation of inflammatory pathways (Takeda et al., 2003; Brown et al., 2011). Later reports identified the ability of TLR family members to recognise likewise endogenous ligands, which accumulate during tissue damage and fibrosis with important functions in the regulation of non-infectious inflammation ( $\mathrm{Yu}$ et al., 2010). Of note, a new role for TLRs in wound healing (Deiters et al., 2004; Macedo et al., 2007) and liver regeneration (Seki et al., 2005) has been reported, suggesting even a regenerative aspect for TLR signalling.

Macrophage-activating lipopeptide of $2 \mathrm{kDa}$ (MALP2) is a bacterial lipopeptide which naturally occurred in mycoplasma species (Muehlradt et al., 1997) and is recognised by a heterodimer of TLR2 and TLR6 (Takeuchi et al., 2000; Takeuchi et al., 2001). Of note, MALP-2 is synthetically available and has been already used in multiple studies. MALP-2 stimulation of the immune response has potential therapeutic implications, e.g., as a mucosal adjuvant for vaccination (Rharbaoui et al., 2002) or to induce lipopolysaccharide cross tolerance (Deiters et al., 2003). In oncology, intratumoural application of MALP-2 leads to significant tumour suppression in mice with pancreatic cancer (Schneider et al., 2004). In a phase I/II trial, injection of MALP-2 into incurable pancreatic tumours lead to prolonged survival of these patients. This was potentially explained by immune activation including attraction of natural killer cells, activation of macrophages and dendritic cells, and lymphocyte infiltration (Schmidt et al., 2007). In addition, MALP-2 exhibits even tissue regenerative potential. Topical treatment of full-thickness excision skin wounds in diabetic mice with MALP-2 led 
to a significantly accelerated wound healing. This effect was accompanied by stimulation of the inflammatory response with activation of macrophages and increased capillary density in the wound bed. Genes encoding for growth factors such as vascular endothelial growth factor (VEGF), and granulocyte-macrophage colony-stimulation factor (GM-CSF) were found to be up-regulated by MALP-2 treatment (Deiters et al., 2004). In this regard we showed that TLR2/6 stimulation by MALP-2 directly promote angiogenesis, a mechanism that is driven by GM-CSF induction in endothelial cells and monocytes (Grote et al., 2010). Moreover, recent data from our group even demonstrated a therapeutic potential of MALP-2 to accelerate endothelial wound healing after interventional vascular injury (Grote et al., 2013). Interestingly, there are in vitro studies showing that MALP-2 can even stimulate bone resorption by an IL-6-dependent mechanism (Piec et al., 1999).

MSCs are able to differentiate into cell types such as osteoblasts, chondrocytes, and adipocytes. The expression of TLRs in MSC has already been proven with important functions for differentiation, migration, proliferation and survival of these cells (Pevsner-Fischer et al., 2007; DelaRosa and Lombardo, 2010). In addition, MSCs are a rich source of soluble pro-angiogenic growth factors such as VEGF in response to different stimuli (Crisostomo et al., 2008). Modulation of local or transplanted MSCs may represent a promising tool for tissue engineering. The aim of the present study was to investigate potential pro-angiogenic effects of MALP-2 on MSCs for the use of therapeutic angiogenesis in tissue engineering. Therefore, we used human MSCs for in vitro studies and MSCs from sheep for subsequent in vivo studies.

\section{Materials and Methods}

\section{Cell culture}

\section{Isolation and cultivation of human MSCs}

20-80 $\mathrm{mL}$ of bone marrow aspirates from the iliac crest were collected from 3 donors undergoing transplantation of cancellous bone. Two patients were operated electively (osteotomy), one underwent dorsal stabilisation for vertebral fracture after trauma. The donors were otherwise healthy and their age ranged between 46 and 55 years. No patient was administered dexamethasone or other steroids before harvesting. At first, the bone marrow aspirates were diluted in a heparin-solution and stored at $4{ }^{\circ} \mathrm{C}$ in the syringe. Within $12 \mathrm{~h}$ after aspiration MSCs were isolated and cultivated as described before (Haasper et al., 2008; Broese et al., 2011). Briefly, bone marrow aspirates were mixed 1:2 with Dulbecco's Phosphate Buffered Saline (PBS, Biochrom, Berlin, Germany) and centrifuged over a Percoll gradient (Biocoll ${ }^{\circledR}$, Biochrom) for $20 \mathrm{~min}$ at $800 \mathrm{~g}$. The white section of the supernatant was resuspended in PBS and centrifuged again for $20 \mathrm{~min}$ at $800 \mathrm{~g}$. The obtained cell pellet was resuspended in Dulbecco's Modified Eagle's Medium (DMEM)/Ham's F-12 culture media (Biochrom) supplemented with $10 \%$ foetal calf serum (FCS, Gibco, Darmstadt, Germany), $100 \mathrm{U} / \mathrm{mL}$ penicillin, $100 \mu \mathrm{g} / \mathrm{mL}$ streptomycin (Gibco, Karlsruhe, Germany), $2.5 \mu \mathrm{g} / \mathrm{mL}$ amphotericin B (Biochrom), plated in $75 \mathrm{~cm}^{2}$ culture flasks (Nunc, Berlin, Germany) and incubated at $37^{\circ} \mathrm{C}$ and $5 \%$ $\mathrm{CO}_{2}$ in a humidified atmosphere. The medium was changed 3 times a week. After reaching confluence at day 14-21, the cells were released with $0.25 \%$ trypsin (Gibco), counted and subcultured in $75 \mathrm{~cm}^{2}$ cell culture flasks (Nunc). Cells between passage 2 and 4 were used for all experiments.

\section{Cultivation of HUVECS}

Human endothelial cells (human umbilical vein endothelial cells, HUVECs) were obtained from Lonza (Cologne, Germany). Cells were cultured in endothelial cell growth medium (EGM-2; Lonza) with growth factors (epidermal growth factor, vascular endothelial growth factor, fibroblast growth factor, insulin-like growth factor-I) supplemented with $2 \%$ FCS, $100 \mathrm{U} / \mathrm{mL}$ Penicillin and $100 \mu \mathrm{g} / \mathrm{mL}$ Streptomycin in gelatin-coated $25 \mathrm{~cm}^{2}$ cell culture flasks (Nunc). For starvation, HUVECs kept in endothelial basal medium (EBM-2, Lonza) without growth factors supplemented with $0.5 \% \mathrm{FCS}, 100 \mathrm{U} / \mathrm{mL}$ penicillin and $100 \mu \mathrm{g} / \mathrm{mL}$ streptomycin $24 \mathrm{~h}$ before experiments. EBM2 medium without growth factors (control) and EGM-2 medium with growth factors (GF) were used as control conditions during experiments. Cells between passage 2 and 4 were used for all experiments.

\section{CD34 $4^{+}$cells}

The source of peripheral blood $\mathrm{CD} 4^{+}$cells was leukapheresis material from healthy donors after stem cell mobilisation with recombinant granulocyte-colony stimulating factor (G-CSF). For isolation of CD34 ${ }^{+}$cells, we used the CliniMACS system (Miltenyi Biotec, Bergisch Gladbach, Germany).

All procedures were approved by the institutional ethical committee of Hannover Medical School, Germany, and were in accordance with the Helsinki Declaration of 1975, as revised in 1983. An informed consent was obtained from all donors.

\section{MALP-2}

MALP-2 was purchased from Axxora GmbH (Loerrach, Germany) and dissolved in $30 \%$ 2-propanol/water to a $1 \mathrm{mg} / \mathrm{mL}$ stock solution. MALP-2 was diluted in cell culture medium for further experiments.

\section{Phalloidin staining}

F-actin filaments of MSCs of passage P2 and P4 were stained with Alexa Fluor ${ }^{\circledR} 488$ phalloidin (1:500, Invitrogen, Carlsbad, CA, USA) and nuclei were stained with 4',6-diamidino-2-phenylindole (DAPI, 1:100,000, Invitrogen) by direct application to the cell culture medium for 2 hours. Pictures from the cells were taken with an inverted microscope (AxioObserver.Z1, Carl Zeiss, Jena, Germany) and a digital camera (AxioCam MRm, Carl Zeiss) at 100x magnification.

\section{Flow cytometry}

Phenotype of human MSCs was analysed on a FACSCalibur flow cytometer (BD Biosciences, Franklin Lakes, NJ, USA). Cells were stained with the following labelled antibodies: CD73-PE, CD271-PE, CD45-APC, CD235- 
APC and additionally with CD34-APC (1:100, all obtained from BD Biosciences). Appropriate IgGs (Invitrogen) were used as isotype controls. Cell purity of human MSCs $\left(\mathrm{PE}^{\mathrm{pos}}, \mathrm{APC}^{\mathrm{neg}}\right.$ ) was always greater than $80 \%$. Additionally, human MSCs were stained with antibodies against TLR2 and TLR6 (1:100, eBioscience, San Diego, CA, USA) and appropriate secondary antibodies labelled with Alexa Flour 488 and 647 (1:100, Invitrogen). Appropriate IgGs (Invitrogen) were used as isotype controls.

\section{Polymerase chain reaction $(\mathrm{PCR})$}

Total RNA from human MSCs was isolated using TriFast-Reagent (peqLAB, Erlangen, Germany) and reverse-transcribed with SuperScript reverse transcriptase (Invitrogen), oligo(dT) primers, and deoxynucleoside triphosphates. Products were amplified using Taq DNA polymerase (Invitrogen). PCR was performed with an initial denaturation step at $95{ }^{\circ} \mathrm{C}$ for 10 min followed by 40 PCR cycles consisting of $95{ }^{\circ} \mathrm{C}$ for $15 \mathrm{~s}, 57{ }^{\circ} \mathrm{C}$ for $30 \mathrm{~s}$, and $72{ }^{\circ} \mathrm{C}$ for $30 \mathrm{~s}$ with oligonucleotides for TLR2 (forward primer: 5' -TCA TTT GGC ATC ATT GGA AA3', reverse primer: 5'-CCA CTT GCC AGG AAT GAA GT-3', 862 bp), TLR6 (forward primer: 5'-GAC CTA CCG CTG AAA ACC AA-3', reverse primer: 5'-GAA TGT GCT TGG TGC ATG AG-3', 921 bp) and GAPDH (forward primer: 5'-ACC ACC ATG GAG AAG GCT GG-3', reverse primer: 5'-CTC AGT GTA GCC CAG GAT GC-3', 527 bp). Oligonucleotides were obtained from MWG-Biotech (Ebersberg, Germany). For visualisation, PCR products were separated on a $1.0 \%$ agarose gel and analysed using a gel image analysis system (GeneGenius, Syngene, Cambridge, UK).

\section{Western blotting}

Proteins from cellular extracts of human MSCs and THP-1 cells were separated by denaturing SDS-PAGE (10\%), and transferred to a PVDF membrane (GE Healthcare, Munich, Germany). Transferred proteins were probed with antibodies against TLR2 (1:500, eBioscience), TLR6 (1:500, Santa Cruz Biotechnology, Santa Cruz, CA, USA) and GAPDH (1:5000, Santa Cruz BiotechnologyVisualization was accomplished using appropriate peroxidase-conjugated secondary antibodies, ECL solution, and ECL film (Hyperfilm ECL, GE Healthcare). Films were visualised using an image analysis system (GeneGenius, Syngene).

\section{Protein array}

$1 \times 10^{6}$ human MSCs of passage $\mathrm{P} 2$ were cultured overnight in $1 \mathrm{~mL}$ DMEM/Ham's F-12 medium per well of a 24-well plate (Nunc). Medium were changed and cells left untreated (control) or were stimulated with $1 \mu \mathrm{g} /$ mL MALP-2. Supernatants were collected $24 \mathrm{~h}$ after stimulation and analysed with a commercial protein array for human angiogenesis-related cytokines and growth factors (RayBiotech, Norcross, GA, USA) according to the manufacturer's instructions. In brief, membranes were blocked for 30 min with blocking buffer and incubated with $2 \mathrm{~mL}$ of supernatants (1:2 diluted with blocking buffer) overnight at $4{ }^{\circ} \mathrm{C}$. After washing, biotin-conjugated antibody cocktail was added and again incubated overnight at $4{ }^{\circ} \mathrm{C}$, followed by a $2 \mathrm{~h}$ incubation with streptavidin- conjugated peroxidase at room temperature. Membranes were incubated with peroxidase substrate and exposed to ECL films (Hyperfilm ECL; GE Healthcare). Films were digitised and quantified densitometrically using an image analysis system (GeneGenius, Syngene) and the software Quantity One (Bio-Rad Laboratories, Hercules, CA, USA).

\section{Enzyme-linked immunosorbent assay (ELISA)}

1x $10^{4}$ human MSCs of passage P2 were cultured overnight in $100 \mu \mathrm{L}$ DMEM/Ham's F-12 medium per well of a 96well plate (Nunc). Medium was changed and cells were left untreated (control) or were stimulated with $1 \mu \mathrm{g} / \mathrm{mL}$ MALP-2. In addition, MSCs were treated with antibodies against TLR2 (25 $\mu \mathrm{g} / \mathrm{mL}$, eBioscience) and TLR6 (25 $\mu \mathrm{g} /$ $\mathrm{mL}$, Santa Cruz) and appropriate control $\mathrm{IgG}(50 \mu \mathrm{g} / \mathrm{mL})$, before stimulation with $1 \mu \mathrm{g} / \mathrm{mL}$ MALP-2. Supernatants were collected $24 \mathrm{~h}$ after stimulation and analysed for VEGF and GM-CSF protein levels by commercial ELISA (R\&D Systems, Minneapolis, MN, USA) according to the manufacturer's protocol with the help of a plate reader ( $\mu$ Quant, BioTek Instruments, Winooski, VT, USA).

\section{Cell migration assay}

$1 \times 10^{5}$ HUVECs in $100 \mu \mathrm{L}$ of EBM-2 were placed in the upper chamber of Transwell cell culture inserts $(8 \mu \mathrm{m}$ pore size; Corning Life Sciences, Amsterdam, The Netherlands). The lower chamber contained $600 \mu \mathrm{L}$ EBM-2 (control) or EBM-2 supplemented with $10 \%$ conditioned medium of human MSCs stimulated for $24 \mathrm{~h}$ with or without MALP-2 $(1 \mu \mathrm{g} / \mathrm{mL})$. EGM-2 with growth factors (GF) was used as positive control. $5 \times 10^{4}$ human MSCs in $100 \mu \mathrm{L} \mathrm{DMEM/}$ Ham's F-12 were placed in the upper chamber of Transwell cell culture inserts ( $8 \mu \mathrm{m}$ pore size; Corning Life Sciences). The lower chamber contained $600 \mu \mathrm{L}$ DMEM/Ham's F-12 with or without MALP-2 $(1 \mu \mathrm{g} / \mathrm{mL})$. DMEM/Ham's F-12 with $10 \%$ FCS was used as positive control. Migration was carried out for $24 \mathrm{~h}$ at $37{ }^{\circ} \mathrm{C}$ and $5 \% \mathrm{CO}_{2}$. Migrated cells into the lower chamber were quantified by counting in a Neubauer chamber using an inverted cell culture microscope (CKX31, Olympus, Hamburg, Germany).

\section{Cell proliferation assay}

$5 \times 10^{3}$ HUVECs per well were seeded in gelatine-coated 96-well tissue culture plates (Nunc) and maintained for $6 \mathrm{~h}$ in $100 \mu \mathrm{L}$ EBM-2 per well. Subsequently, cells were cultured in $100 \mu \mathrm{L}$ EBM-2 (control) or in EBM-2 supplemented with $10 \%$ conditioned medium of human MSCs stimulated for $24 \mathrm{~h}$ with or without MALP-2 (1 $\mu \mathrm{g} /$ $\mathrm{mL}$ ). EGM-2 with growth factors (GF) was used as positive control. $5 \times 10^{3}$ human MSCs per well were seeded in 96well tissue culture plates (Nunc) and maintained for $6 \mathrm{~h}$ in $100 \mu \mathrm{L}$ DMEM/Ham's F-12 per well. Subsequently, cells were cultured in $100 \mu \mathrm{L}$ DMEM/Ham's F-12 (control) or in DMEM with MALP-2 $(1 \mu \mathrm{g} / \mathrm{mL})$. DMEM/Ham's F-12 with $10 \%$ FCS was used as positive control. Cell proliferation was measured on the basis of DNA synthesis by 5-bromo-2'-deoxyuridine (BrdU) incorporation. The amount of BrdU incorporation for the last $4 \mathrm{~h}$ of the $24 \mathrm{~h}$ cultivation period was determined with a commercial colorimetric quantification kit (Roche Diagnostics, Mannheim, Germany) according to the manufacturer's 
protocol by measuring the absorbance at $450 \mathrm{~nm}$ with a plate reader ( $\mu$ Quant; Bio-Tek Instruments, Winooski, VT, USA).

\section{Matrigel angiogenesis assay (endothelial tube formation)}

$7.5 \times 10^{3}$ HUVECs per well were seeded on 96-well tissue culture plates (Nunc) previously coated with $25 \mu \mathrm{L}$ Matrigel (growth factor-reduced; BD Biosciences). Cells were cultured in $100 \mu \mathrm{L}$ EBM-2 (control) or in EBM-2 supplemented with $10 \%$ conditioned medium of human MSCs stimulated for $24 \mathrm{~h}$ with or without MALP-2 ( $1 \mu \mathrm{g} / \mathrm{mL})$. EGM-2 with growth factors (GF) was used as positive control. After $24 \mathrm{~h}$ of culturing, tube-like structures were staining with the intracellular fluorescent dye 2',7'-bis-(2-carboxyethyl)-5-(and-6)-carboxyfluorescein acetoxymethyl ester (Sigma-Aldrich Chemie, Taufkirchen, Germany) diluted 1:5000 in phosphate-buffered saline for $15 \mathrm{~min}$ and subsequently visualised using an inverted fluorescence microscope (AxioObserver.Z1, Carl Zeiss Microimaging) and a digital camera (AxioCam MRm, Zeiss) at 50x magnification. Endothelial tube length per picture was determined by computer-assisted morphometric analysis (ImageJ, NIH, Bethesda, MD, USA) and presented as cumulative tube length in $\mu \mathrm{m}$.

\section{Matrigel angiogenesis assay (endothelial tube outgrowth)}

The thoraco-abdominal aorta was isolated from C57BL/6 mice with the help of a surgical microscope (Stemi DV4 Spot, Zeiss). The aorta was cleaned of connective tissue and fat, and the adventitia were removed. Subsequently, the aorta was cut in segments of approximately $1 \mathrm{~mm}$ length and was placed on 48-well tissue plates (one segment per well, Nunc) previously coated with $50 \mu \mathrm{L}$ Matrigel (growth factor-reduced; BD Biosciences). Segments were cultured in $1 \mathrm{~mL}$ EBM-2 (control) or EBM-2 supplemented with $10 \%$ conditioned medium of human MSCs stimulated for $24 \mathrm{~h}$ with or without MALP-2 $(1 \mu \mathrm{g} / \mathrm{mL})$. EGM-2 with growth factors (GF) was used as positive control. After 7 days on Matrigel, the outgrowths of endothelial tubes were visualised using an inverted fluorescence microscope (AxioObserver.Z1, Zeiss) and a digital camera (AxioCam MRc, Zeiss) at $25 \mathrm{x}$ magnification. Tube length per aortic ring was determined by computer-assisted morphometric analysis (Image J) and presented as average tube length in $\mu \mathrm{m}$. Endothelial origin of outgrowing tubes were confirmed by staining with fluorescein-labelled isolectin B4 (1:100, Vector Laboratories, Burlingame, CA, USA).

\section{Sheep model of tissue engineering}

Animal experiments were conducted at the University of Veterinary Medicine Hannover. The protocol was approved by the local ethics committee in accordance with the German federal animal welfare legislation (Department for Veterinary Affairs, Oldenburg, Germany, AZ:08/1621).

Eigtheen healthy adult female German Blackheaded sheep with an average body weight of $79.0 \mathrm{~kg}$ (range 64.5-85.0 kg) were used in the study. After intravenous (i.v.) induction ( $0.2 \mathrm{mg} / \mathrm{kg}$ midazolam, $5 \mathrm{mg} / \mathrm{kg}$ propofol), anaesthesia was maintained with isoflurane delivered in $100 \%$ oxygen $(1 \mathrm{~L} / \mathrm{min})$. Additionally, butarphanol $(0.1 \mathrm{mg} / \mathrm{kg}$ intramuscularly (i.m.)), carprofen $(4 \mathrm{mg} /$ $\mathrm{kg}$ subcutaneously (s.c.)), and buprenorphine $(10 \mu \mathrm{g} /$ $\mathrm{kg}$ s.c.) were applied for analgesia. Monitoring during surgery included blood pressure, electrocardiogram, rectal temperature, and haemoglobin oxygen saturation. Surgery was performed in the right lateral position.

A muscle chamber of left latissimus dorsi muscle was prepared and gamma-sterilised $\beta$-tricalciumphosphate (TCP) cylinders (ChronOS ${ }^{\circledR}$, Synthes, Umkirch, Switzerland) were implanted. The porosity was $60-80 \%$ and the pore size 100-500 $\mathrm{nm}$. The cylinders had a length of $25 \mathrm{~mm}$ and a diameter of $14 \mathrm{~mm}$ and contained a standardised $7 \mathrm{~mm}$ hollow-drilled shaft. After hollow drilling, the cylinders were split longitudinally by a piezoelectric instrument. The artery/vein of the latissimus dorsi muscle was prepared microsurgically and positioned in the cylinder along the longitudinal split into the hollow drilling hole under sterile conditions. The $\beta$-TCP cylinders were differently loaded before the procedure. Three groups were created, each group consisted of 6 animals: group 1 (control group), group 2 (spongiosa group), group 3 (MALP-2 group).

For group 1 (control group): The $\beta$-TCP cylinders were saturated with $10 \mathrm{~mL}$ of autologous blood that was taken from the catheter in the jugular vein immediately prior to implantation. The blood was aspirated through the $\beta$-TCP cylinders by a special cartridge system ( $\beta$-TCP kit, Synthes) until the cylinders were fully soaked. The scaffold was implanted into the left latissimus dorsi region via a $10 \mathrm{~cm}$ skin incision surrounding a perforator vessel bundle and the soft tissue wound was closed in layers using Vicryl 2.0 sutures.

For group 2 (spongiosa group): The $\beta$-TCP cylinder was blood-soaked using the $\beta$-TCP kit as described above. Then the scaffold was implanted into the left latissimus dorsi region via a $10 \mathrm{~cm}$ skin incision surrounding a perforator vessel bundle. After this, three bone punches ( $5 \mathrm{~mm}$ diameter) were harvested from the left iliac crest. The autologous cancellous bone was reduced into small pieces with an electric bone mill and then directly loaded on the cylinder in a surgical seeding procedure. Soft tissue wound was closed in layers using Vicryl 2.0 sutures.

For group 3 (MALP-2 group): Two surgical procedures were performed in this group. Three weeks prior to implantation, autologous bone marrow aspirates from the posterior left iliac crest were harvested. After a stab incision, the anterior and posterior outlines of the iliac crest were palpated by a Yamshidi aspiration needle. Then, the needle was inserted centrally and pushed into the marrow cavity approximately $5 \mathrm{~cm}$ deep following the contour of the cavity. MSCs were enriched as described above and cells were aspirated directly through a silicone tube into the porous scaffold using an aspiration technique described previously (Jagodzinski et al., 2008). The scaffolds of $2 \beta$-TCP-cylinders were placed into a custommade bioreactor system. The bioreactor was filled with a medium (see below) and cultivated under continuous perfusion for 3 weeks. Of note, the bioreactor system has been described and used for clinical case studies of tissue-engineered bone before (Hesse et al., 2010). 
A
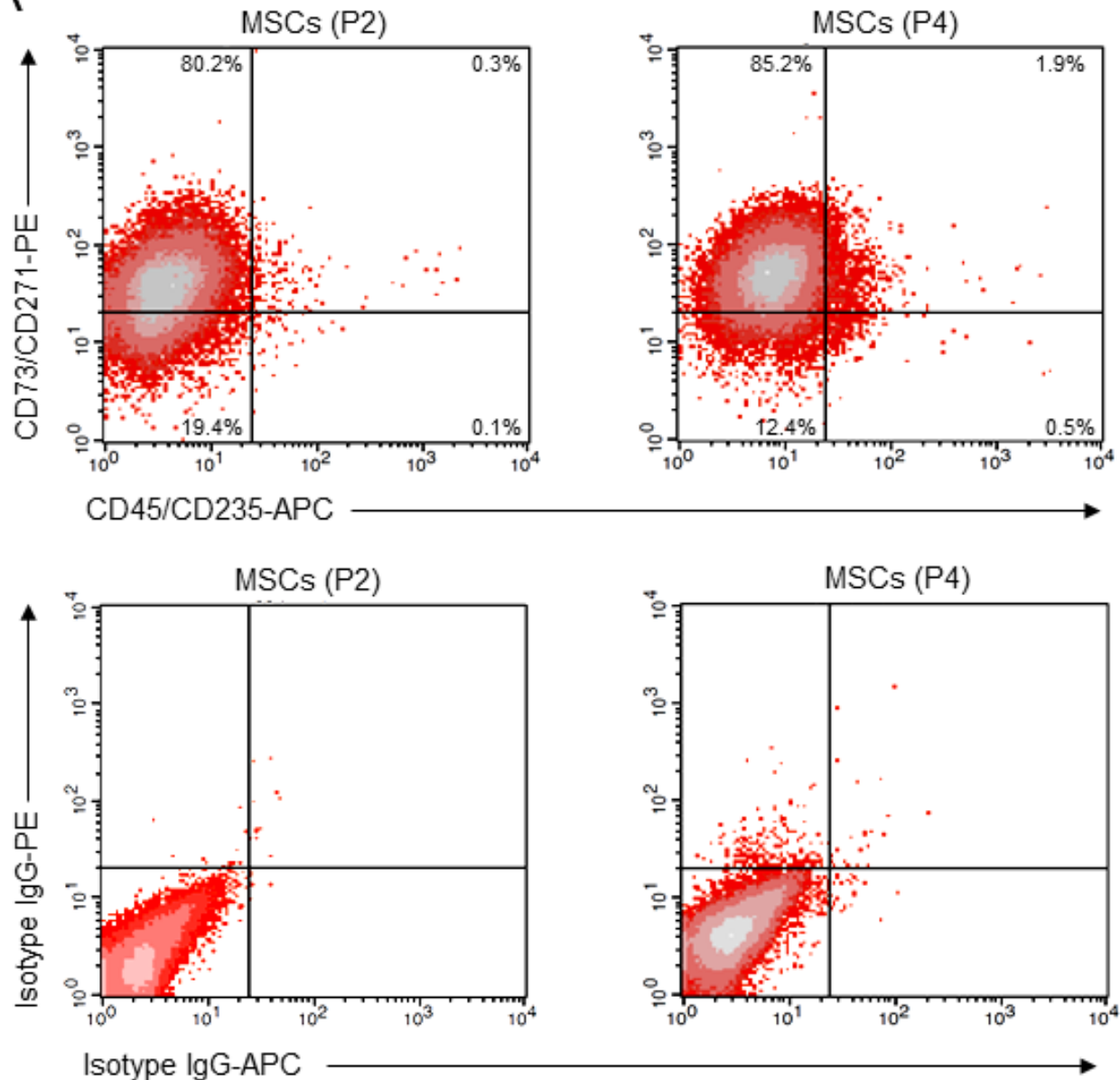

Isotype lgG-APC

B
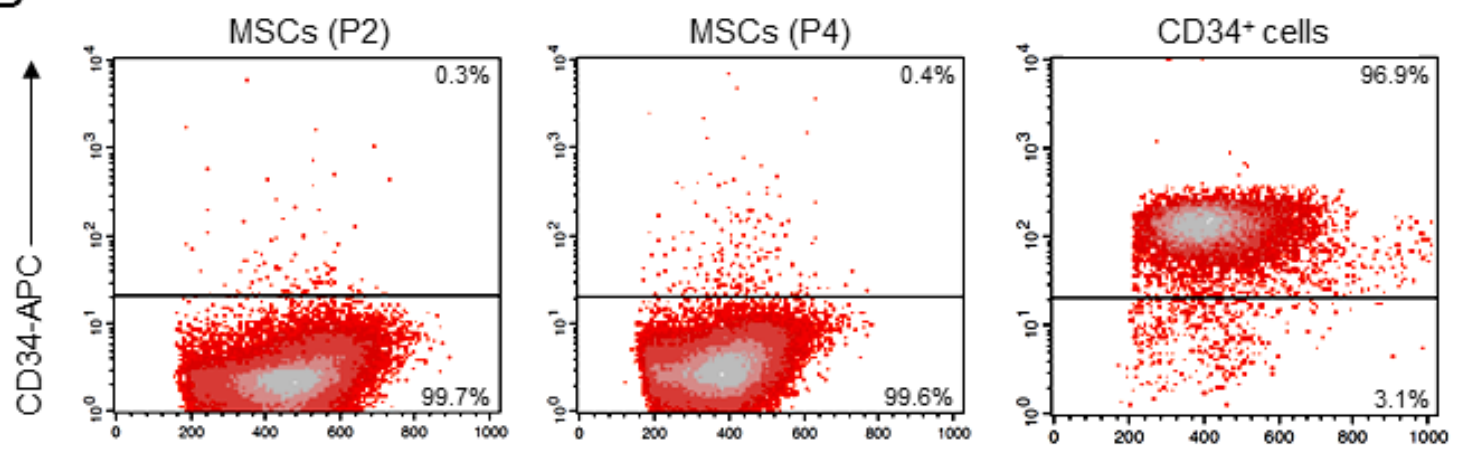

FSC-H
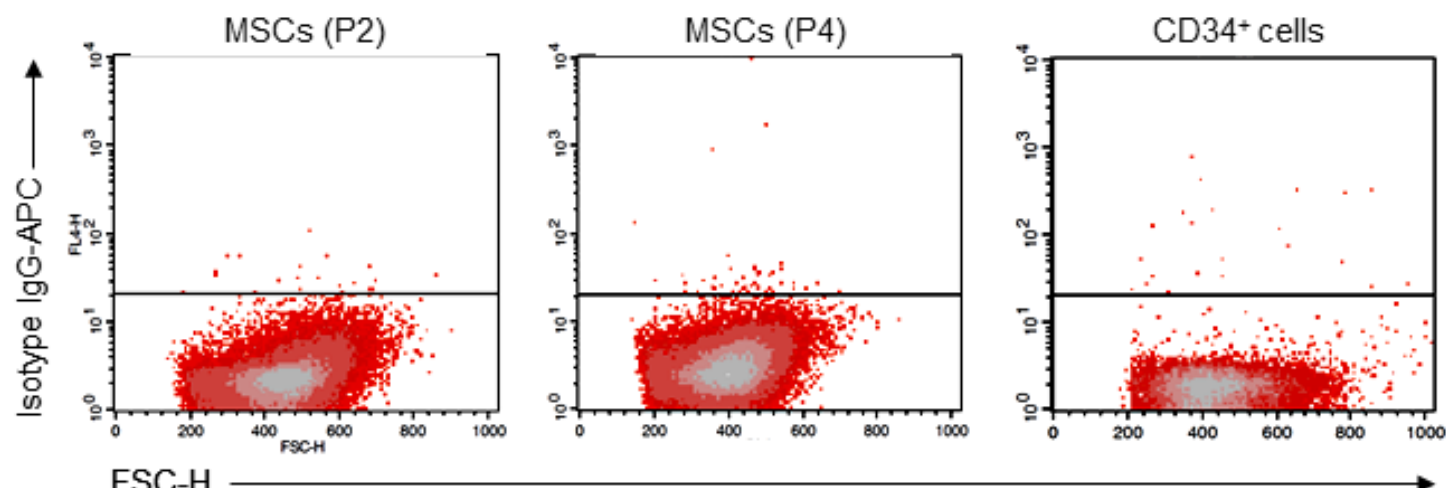

Fig. 1. Analysis of mesenchymal markers on human MSCs. Expression of CD73, CD271, CD45, CD235 (A) and CD34 (B) on human MSCs of passage (P) 2 and 4 was verified by flow cytometry using APC- and PE-labelled antibodies. Appropriate APC- and PE-labelled isotype IgG were used as controls. 
Briefly, it consists out of a culture chamber hosting a porous scaffold and an inflow and two outflow valves. For the cell seeding, one outflow valve is closed and one is open to permit aspirates to propagate through the scaffold pores. The bioreactors were filled with saline containing $1000 \mathrm{U}$ of heparin $\left(\right.$ Liquemin $\left.^{\circledR}\right)$. The same solution was used to irrigate the aspiration syringe before its use. The bioreactor was rotated at $5^{\circ}$ per minute for $24 \mathrm{~h}$. Then, the scaffolds were perfused with $500 \mathrm{~mL}$ DMEM Ham's F-12 medium (Biochrom) containing $10 \%$ FCS, $100 \mathrm{U} /$ $\mathrm{mL}$ penicillin and $200 \mu \mathrm{g} / \mathrm{mL}$ streptomycin (Biochrom), $0.5 \mu \mathrm{g} / \mathrm{mL}$ amphotericin B (Biochrom), $5 \mu \mathrm{g} / \mathrm{mL}$ ascorbic acid (Sigma-Aldrich), $0.02 \mathrm{nM} / \mathrm{mL}$ dexamethasone (Merck, Darmstadt, Germany) (Jagodzinski et al., 2004). In addition, the medium was supplemented with $30 \mathrm{ng} / \mathrm{mL}$ MALP-2. The bioreactor was kept in an incubator at $37^{\circ} \mathrm{C}$ and culture was performed with a media flow of $2 \mathrm{~mL} /$ min and $5 \% \mathrm{CO}_{2}$ (Bancroft et al., 2002). Every third day, $50 \mathrm{~mL}$ of culture media were exchanged. After 21 days, the bioreactors were disconnected and transferred to the operating room at $5{ }^{\circ} \mathrm{C}$ temperature.

Directly after removal from the bioreactor the loaded $\beta$-TCP cylinders were implanted onto the vessel bundle in the left latissimus dorsi muscle region as described above. Soft tissue wound was closed in layers using Vicryl 2.0 sutures. No extra harvesting of cancellous bone out of the iliac crest was performed. After 6 months, all bioartificial grafts were explanted and all animals were euthanised in deep sedation (midazolam $1 \mathrm{mg} / \mathrm{kg}$ i.m., propofol $5 \mathrm{mg} / \mathrm{kg}$ i.v., and pentobarbital $80 \mathrm{mg} / \mathrm{kg}$ i.v.). After explantation, the graft was fixed in $3.5 \%$ neutral buffered formalin, embedded in methylmethacrylate (MMA) and sectioned perpendicular to the axis of the cylinder using a modified inner-hole diamond saw. Undecalcified slices of $30 \mathrm{~mm}$ thickness were surface stained with alizarine-methylene blue for standard light microscopy and histomorphometric analysis. Digital images of each slide were obtained using a Zeiss AxioImager MI Microscope fitted with an AxioCam MRc digital camera and AxioVision 4.5 software (Carl Zeiss, Oberkochen, Germany). The AxioVision module MosaiX was used to scan the total specimen. Digital images of the entire cross-section provided the basis for further analysis. Vascular structures (capillaries and arterioles) with a distinguishable lumen were counted in the area around the artery/vein and in the area of the scaffold.

\section{Statistical analysis}

Data are presented as the mean \pm standard error of the mean (SEM). Comparisons were made by the 2-tailed Student's $t$-test for independent samples. Values of $P$ less than 0.05 were considered statistically significant.

\section{Results}

\section{Characterisation of human MSCs and analysis of TLR2 and TLR6 expression}

MSCs were isolated from bone marrow aspirates from the iliac crest of patients undergoing cancellous bone transplantation and cultivated in vitro. Analysis by flow cytometry showed that the cells were highly positive
(>80\%) for the mesenchymal markers CD73 and CD271 and negative for the leukocyte marker CD45 and the erythroid marker CD235 (Fig. 1A). Expressions of the mesenchymal markers were found to be comparable in MSCs of passage 2 and 4. Of note, MSCs were negative for the haematopoietic marker CD34 excluding contamination with haematopoietic bone marrow cells (Fig. 1B).

Since human MSCs between passage 2 and 4 were used for all subsequent experiments cells were initially characterised by phalloidin staining visualising F-actin filaments of the cytoskeleton. Cultured MSCs appeared homogenous with apparently no morphological difference between passage 2 and 4 (Fig. 2A). Next, we tested human MSCs for the expression of the MALP-2 receptors TLR2 and TLR6. Expression of TLR2 and TLR6 was detected on mRNA level by PCR (Fig. 2B) on protein level by Western blot (Fig. 2C) and on the cell surface by flow cytometry (Fig. 2D) and found to be comparable between passage 2 and passage 4 .

\section{MALP-2 promotes migration but not proliferation of human MSCs}

We first assessed direct cellular effects of MALP-2 on human MSCs. Exposure to MALP-2 enhanced MSC motility since they significantly migrated alongside a MALP-2 gradient (Fig. 3A). However, MALP-2 did not show any mitogenic effects on MSCs because cell proliferation was not enhanced upon MALP-2 treatment (Fig. 3B).

\section{Conditioned medium from MALP-2-stimulated human MSCs enhances migration, proliferation and tube formation of endothelial cells in vitro}

Next, we investigated whether human MSCs exposed to MALP-2 may promote angiogenic properties of endothelial cells in a paracrine manner. Therefore, we used conditioned medium from MALP-2-stimulated human MSCs which was compared to conditioned medium from untreated human MSCs. Angiogenesis critically depends on migration and proliferation of endothelial cells; we addressed these issues in vitro using human endothelial cells (HUVECs). Compared to conditioned medium from untreated cells we observed significantly enhanced endothelial cell migration and proliferation with conditioned medium from MALP2-stimulated human MSCs. Of note, already conditioned medium from untreated human MSCs increased migration and proliferation of HUVECs (Fig. 4A,B). Angiogenesis describes the process of vessel sprouting from pre-existing vessels. Therefore, we investigated the generation of tubelike structures from HUVECs on Matrigel in vitro. We found that conditioned medium from MALP-2-stimulated human MSCs significantly increased the tube-like structure network on Matrigel as compared to conditioned medium from untreated human MSCs (Fig. 4C,D). In addition, we performed another angiogenesis assay in vitro. Therefore, we isolated and subsequently cultivated murine aortic rings on Matrigel. In turn, conditioned medium from MALP-2 stimulated human MSCs significantly enhanced the outgrowth of endothelial tubes from aortic rings as compared to conditioned medium from untreated human MSCs (Fig. 4E,F). 
Fig. 2. Morphological characterisation and TLR2 and TLR6 expression in human MSCs. Morphological appearance and expression of TLR2 and TLR6 was analysed in human MSCs of passage (P) 2 and 4. (A) Immunofluorescent staining of human MSCs of passage 2 and 4 with Alexa Fluor ${ }^{\circledR}$ 488 phalloidin and DAPI. Representative picture are shown. Scale bars $=100 \mu \mathrm{m}$. (B) TLR2 and TLR6 mRNA expression was analysed by PCR. GAPDH expression is shown as loading control. Human monocytic THP-1 cells were used as positive control, $\mathrm{H}_{2} 0$ as negative control. (C) Protein expression was analysed by Western Blot. GAPDH expression is shown as loading control. Human monocytic THP-1 cells were used as positive control. (D) Cell surface expression was analysed by flow cytometry. Filled graphs represent TLR2 and TLR6 expression. Open graphs represent isotype controls. Representative pictures of 3 independent experiments are shown.
A
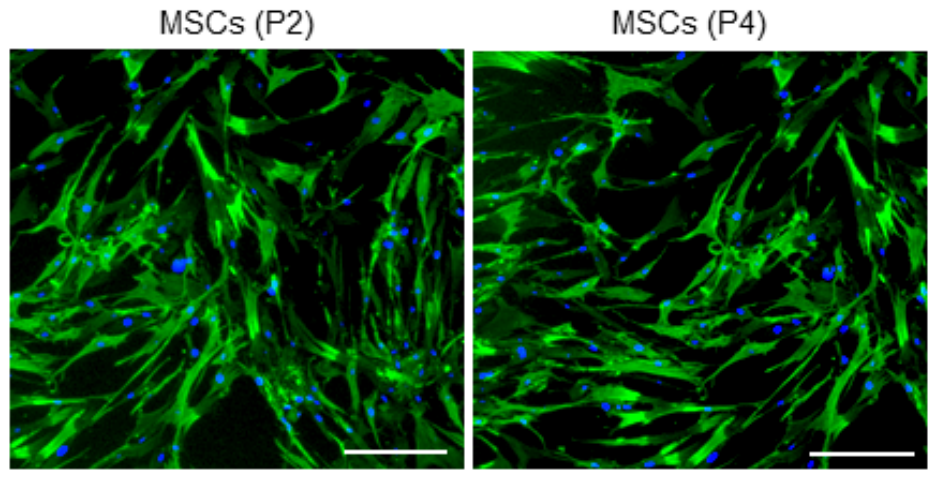

B

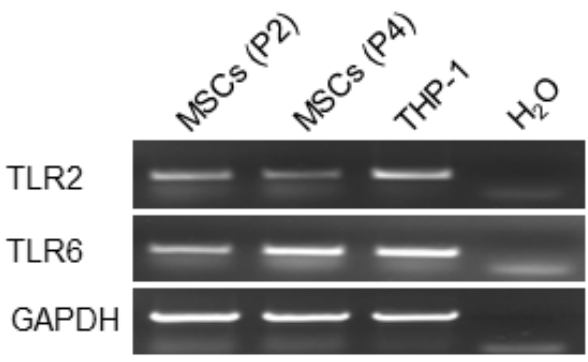

C

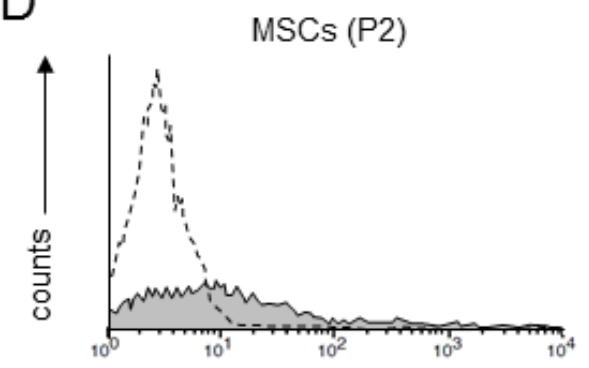

TLR2-Alexa 647

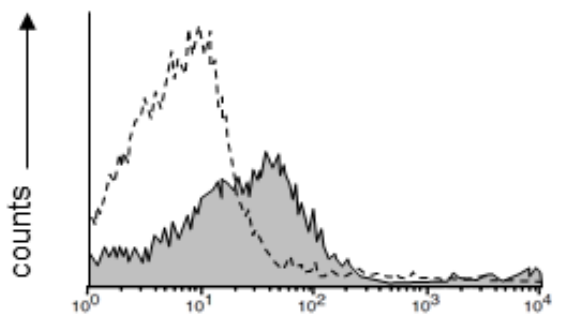

TLR6-Alexa 488
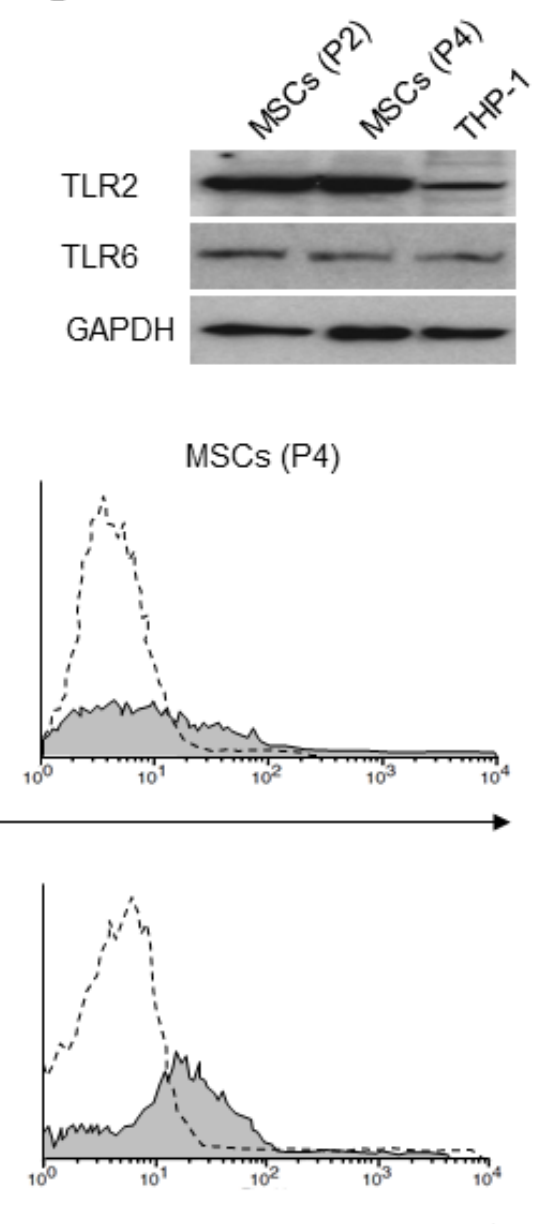

MSCs (P4)

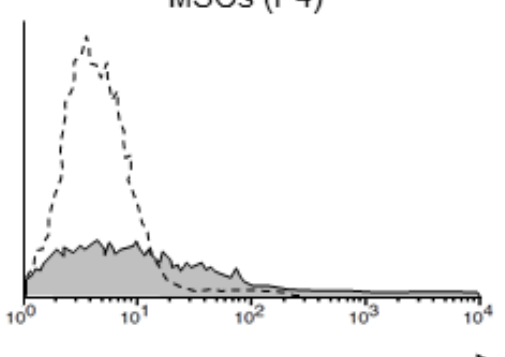

\section{MALP-2 induces the release of growth factors from human MSCs}

To study the potential underlying mechanism for the observed angiogenic processes, we investigated factors that are released by human MSCs in response to MALP-2 and might be involved in angiogenesis. To this end, we stimulated human MSCs with MALP-2 and analysed the conditioned medium with the help of a commercially available protein array specific for angiogenesis-related cytokines and growth factors. Most factors on the array were already released by untreated human MSCs. However, several factors were released to a greater extend when human MSCs were stimulated with MALP-2 (Fig. $5 \mathrm{~A}, \mathrm{~B})$. Among the strongest induced factors we identified GM-CSF (3.0-fold), monocyte chemotactic protein (MCP)3 (6.2-fold), MCP-4 (2.9-fold) and platelet endothelial cell adhesion molecule (PECAM)-1 also known as CD31 (2.0-fold).

We performed further analysis of the conditioned medium by ELISA to confirm our protein array data for GM-CSF which we recently described as an autocrine factor of endothelial cells responsible for MALP-2dependent angiogenesis. (Grote et al., 2010). In addition; we investigated the major angiogenic factor VEGF, which 
A

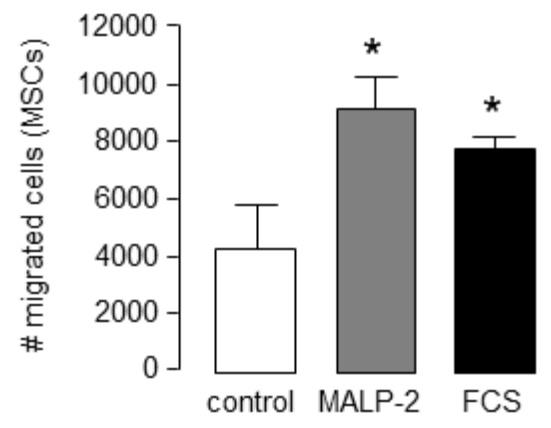

$\mathrm{B}$

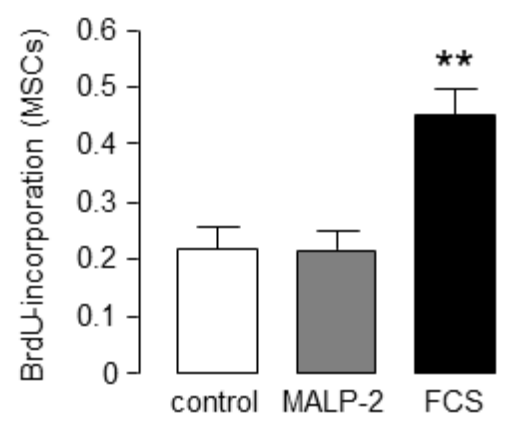

Fig. 3. MALP-2 enhances migration but not proliferation of human MSCs in vitro. Effects of MALP-2 (1 $\mu \mathrm{g} / \mathrm{mL})$ on migration and proliferation of human MSCs. (A) Migration of human MSCs $\left(5 \times 10^{4}\right)$ was carried out in Transwell cell culture inserts for $24 \mathrm{~h}$. (B) Proliferation of human MSCs $\left(5 \times 10^{3}\right)$ was determined by BrdU incorporation for $24 \mathrm{~h}$ and given in $\mathrm{OD}_{450 \mathrm{~nm}} .10 \% \mathrm{FCS}$ was used as positive control. $* P<0.05, * * P<0.01$ vs. control, error bars represent SEM, $n=4-5$.

was not represented on the array. We detected a significant increase in GM-CSF and VEGF levels in the conditioned medium of MALP-2-stimulated human MSCs as compared to conditioned medium of not stimulated MSCs. MALP2-dependent release of these factors could be blocked with antibodies against TLR2 and TLR6 demonstrating their important role in the process. Unspecific control IgG showed no effect (Fig. 5C,D).

\section{Implantation of MALP-2-treated autologous MSCs enhanced vessel density in the latissimus dorsi muscle of sheep}

Finally, we performed a tissue engineering approach in sheep to assess angiogenesis in vivo. $\beta$-TCP cylinders loaded with autologous blood (control), autologous spongiosa or autologous MSCs co-cultivated with MALP2 in a bioreactor system for 3 weeks were implanted into the left latissimus dorsi muscle of sheep. After 6 months vascular structures (capillaries and arterioles) were quantified in explanted grafts. Compared to the control group we found significantly more vessels in the MSCs + MALP-2 group in the region around the artery/vein $(80.4 \pm 7.3$ vs. $29.2 \pm 6.3, P<0.01)$ as well as in the scaffold $(67.6 \pm 9.0$ vs. $38.8 \pm 4.7, P<0.05)$ (Fig. 6A,B).

\section{Discussion}

The major findings of the present study are as follows: (1) the MALP-2 receptors TLR2 and TLR6 are expressed in human MSCs; (2) MALP-2 directly induces migration of human MSCs; (3) MALP-2 stimulation of human MSCs enhances migration, proliferation and tube formation of endothelial cells in a paracrine manner; (4) MALP-2 induces the secretion of cytokines and growth factors from human MSCs; and (5) MALP-2 treated MSCs enhances vessel density in a sheep model of bone tissueengineering. Collectively, our study demonstrates that TLR2/6 stimulation of human MSCs by MALP-2 enhances angiogenic processes in a paracrine manner which could be used for therapeutic angiogenesis, e.g., in tissueengineering of bone.

Transplantation of stem/progenitor cells are considered as potential therapy for inflammatory disorders, tissue repair, and gene delivery, among others (Rameshwar, 2012). In this regard, a wide range of different type of stem cells such as embryonic stem cells, haematopoietic stem cells, MSCs and in the recent past induced pluripotent stem cells have been used (Armstrong et al., 2012). The big advantage of the MSCs - used in the present study is their relatively easy availability by isolation from bone marrow or from adipose tissue. MSCs have been already established for the treatment of various diseases including graft-versus-host disease, Crohn's disease, myocardial infarction, stroke, bone defects, diabetes, and wound repair, experimentally but also in various clinical studies (Vemuri et al., 2011; Wang et al., 2011). Sufficient vascularisation of the engineered tissue is a crucial step in tissue-engineering in general and just as well accepted for tissue engineering of bone. Therefore, the simultaneous stimulation of osteogenic cell proliferation and angiogenesis remains one of the major challenges while developing substitute tissues for large scale bony defects (Kanczler and Oreffo, 2008; Gómez-Barrena et al., 2011). MSCs are multipotent cells that participate in the structural and functional maintenance of connective tissues under normal homeostasis and are able to differentiate into several mesodermal cell lineages like adipocytes, chondrocytes, myocytes, osteocytes, and cells of haematopoietic supportive stroma (Pittenger et al., 1999). However, MSCs have been shown to have multifaceted roles in the modulation of angiogenesis. On the one hand, MSCs act as mediators of angiogenesis during tissue repair following injury by the generation of bioactive molecules (Wu et al., 2007). On the other hand, MSCs serve comparable roles in cancer by homing to developing tumours, where they exacerbate cancer cell proliferation and foster tumour angiogenesis (Cuiffo and Karnoub, 2012).

Mammalian TLRs are homologues of the Drosophila Toll protein and were discovered in the mid-90s of the last 
A

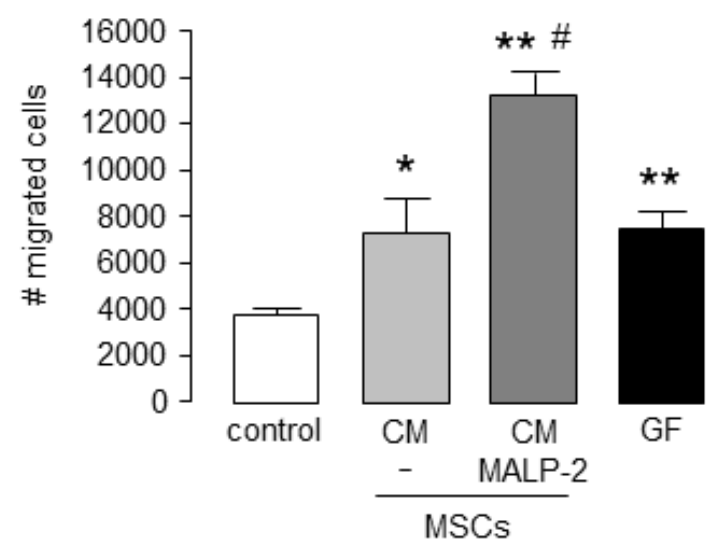

C
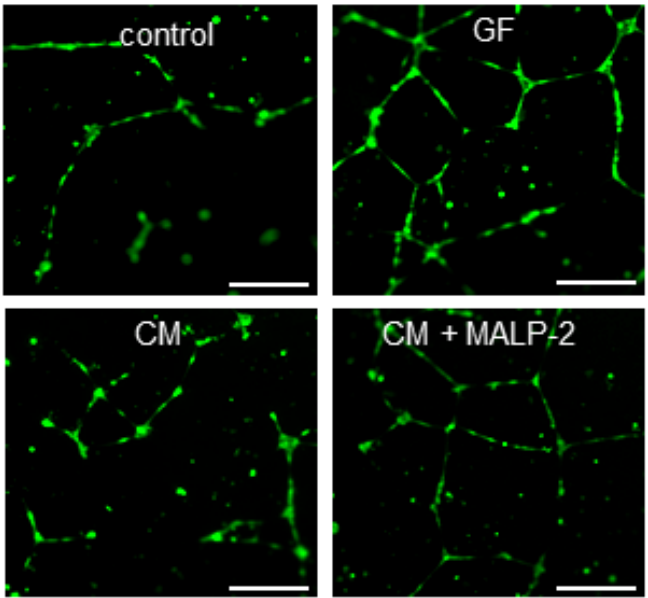

E
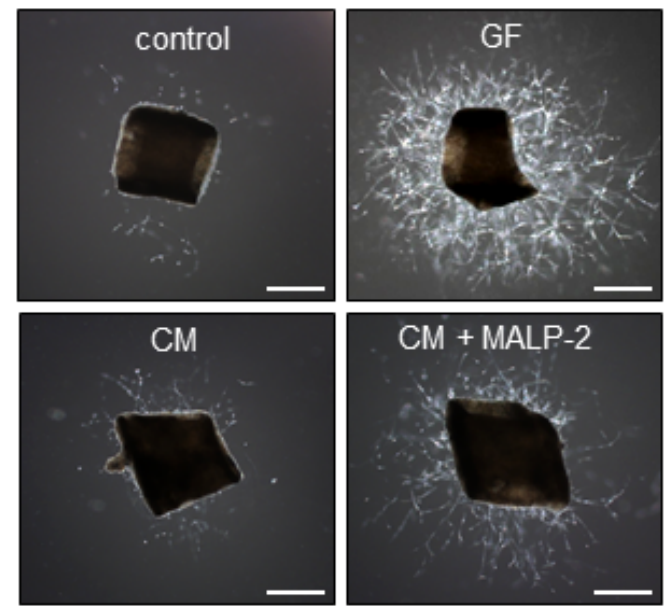

B
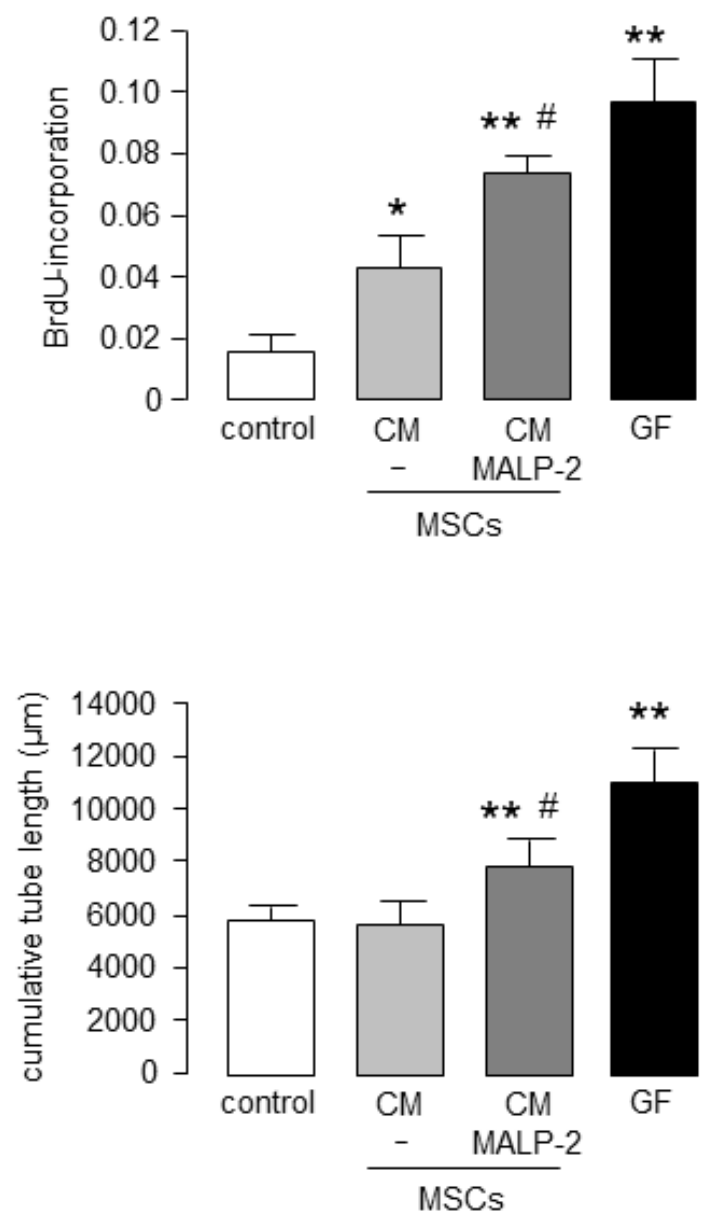

F

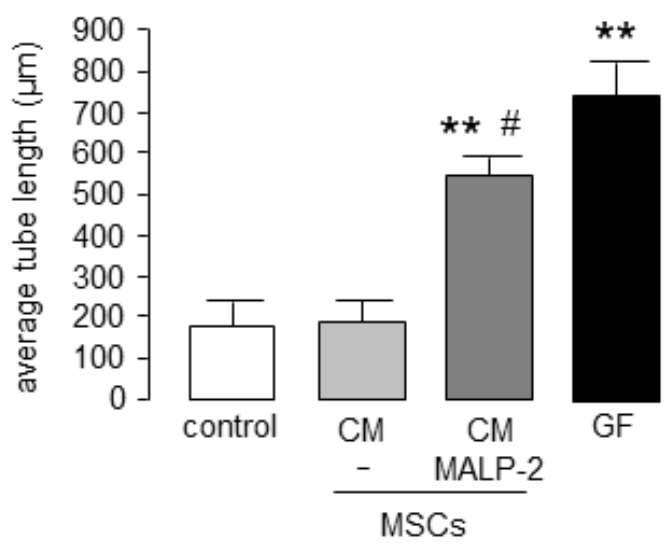

Fig. 4. Conditioned medium from MALP-2-stimulated human MSCs enhances migration, proliferation and tube formation of endothelial cells. Effect of conditioned medium from human MSCs not stimulated (-) were compared with conditioned medium from human MSCs stimulated with MALP-2 $(1 \mu \mathrm{g} / \mathrm{mL})$ for $24 \mathrm{~h}$. (A) Migration of HUVECs $\left(1 \times 10^{5}\right)$ was carried out in Transwell cell culture inserts for $24 \mathrm{~h}$. (B) Proliferation of HUVECs $\left(5 \times 10^{3}\right)$ was determined by BrdU incorporation for $24 \mathrm{~h}$ and given in $\mathrm{OD}_{450 \mathrm{~nm}}$. (C) Pictures represent BCECF-AM stained tube-like structures of HUVECs on Matrigel after $24 \mathrm{~h}$. Scale bars $=250 \mu \mathrm{m}$. (D) Cumulative endothelial tube-length per picture were quantified. (E) Pictures represent the outgrowth of endothelial tubes from murine aortic segments on Matrigel after 7 days. Scale bars $=500 \mu \mathrm{m}$. (F) Average tube length per aortic ring were quantified. Endothelial cell medium with growth factors (GF) was used as positive control. ${ }^{*} P<0.05$, ${ }^{* *} P<0.01$ vs. control, ${ }^{\#} P<0.05$ vs. not stimulated $(-)$, error bars represent SEM, $n=4-5$. CD indicates conditioned medium. 

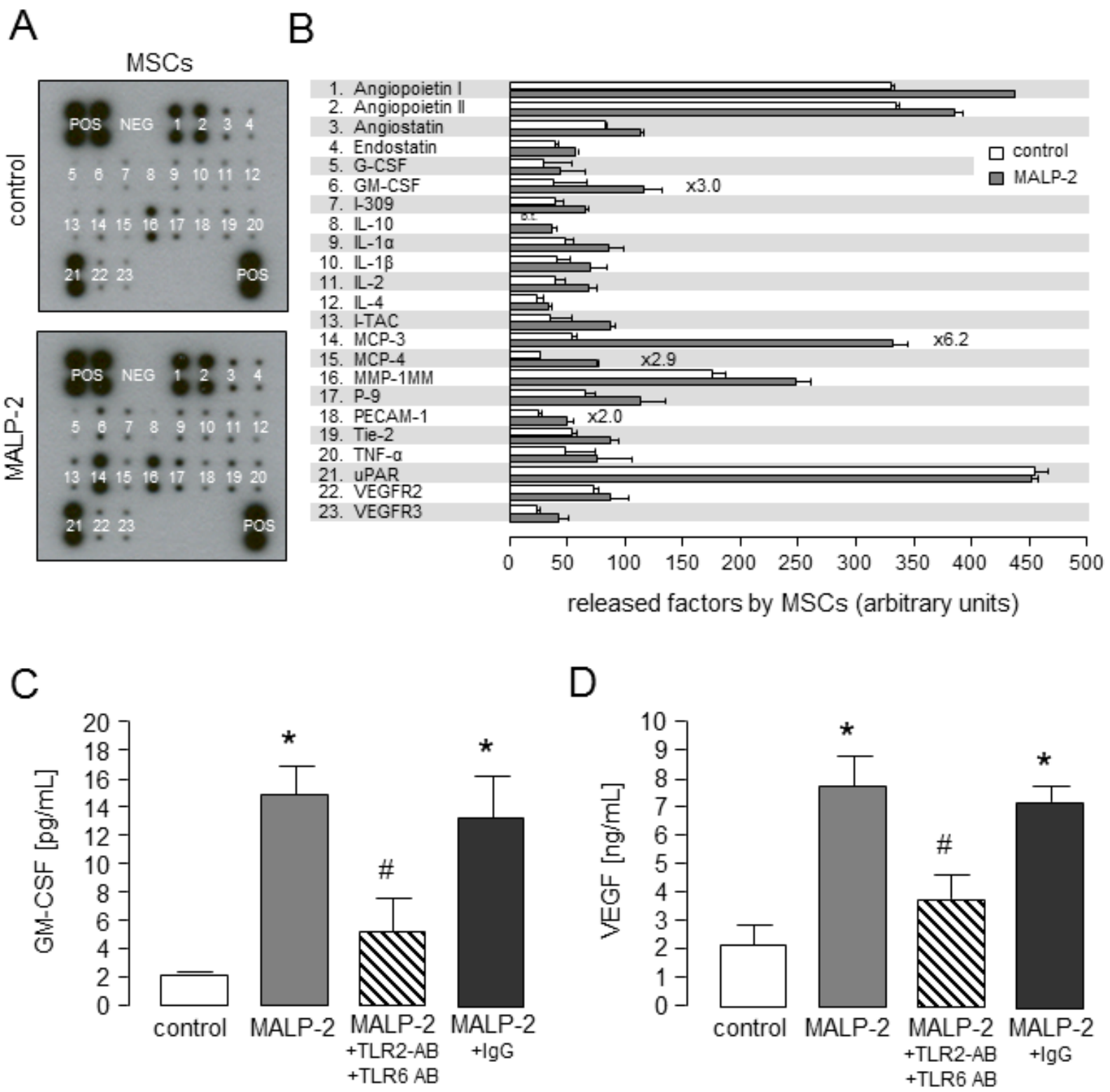

Fig. 5. MALP-2 induces the release of growth factors from human MSCs. (A) Images represent protein array membranes specific for human angiogenesis-related factors. Membranes were incubated with conditioned medium from human MSCs not stimulated (control) or stimulated with MALP-2 $(1 \mu \mathrm{g} / \mathrm{mL})$ for $24 \mathrm{~h}$. POS indicates positive control; NEG, negative control. (B) Relative dot intensities were quantified. b.t. indicates below threshold. (C) GMCSF and (D) VEGF levels in conditioned medium from human MSCs not stimulated (control) or stimulated with MALP-2 $(1 \mu \mathrm{g} / \mathrm{mL})$ for $24 \mathrm{~h}$ as assessed by ELISA. AB indicates antibody $(25 \mu \mathrm{g} / \mathrm{mL}$ each $)$. Unspecific IgG $(50 \mu \mathrm{g} /$ $\mathrm{mL}$ ) was used as antibody control. ${ }^{*} P<0.05$ vs. control, ${ }^{\#} P<0.05$ vs. MALP-2, error bars represent SEM, $n=3$.

century (Taguchi et al., 1996; Medzhitov et al., 1997). Initially, they were exclusively considered as sentinels of the immune system in order to organise the body's pathogen defence in response to PAMPs of bacterial and viral origin by the activation of classical inflammatory signalling pathways such as the mitogen-activated protein kinase (MAPK) cascade or nuclear factor- $\kappa \mathrm{B}(\mathrm{NF}-\kappa \mathrm{B})$ (Brown et al., 2011). Over the years more and more TLR members - more than 10 in mice and human - have been discovered, which act as homo- or heterodimers. At the same time, the number of identified exogenous TLR ligands continuously increased and even endogenous TLR ligands, which mainly accumulate during tissue damage and fibrosis, have been described (Yu et al., 2010). Furthermore, more recent work suggested a new role for TLRs in tissue regeneration and wound healing (Deiters et al., 2004; Seki et al., 2005; Macedo et al., 2007). Likewise, the diacetylated lipopeptide MALP-2 - initially isolated from Mycoplasma species (Muehlradt et al., 1997) - was first described to activate immune cells, i.e. macrophages, via a heterodimer of TLR2 and TLR6 (Takeuchi et al., 2000; Takeuchi et al., 2001). MALP-2 is so far one of the few definitely identified natural ligands signalling via this pathway. Of note, MALP-2 also exhibits a remarkable therapeutic potential and has been successfully used in different experimental and even clinical studies, ranging 
A
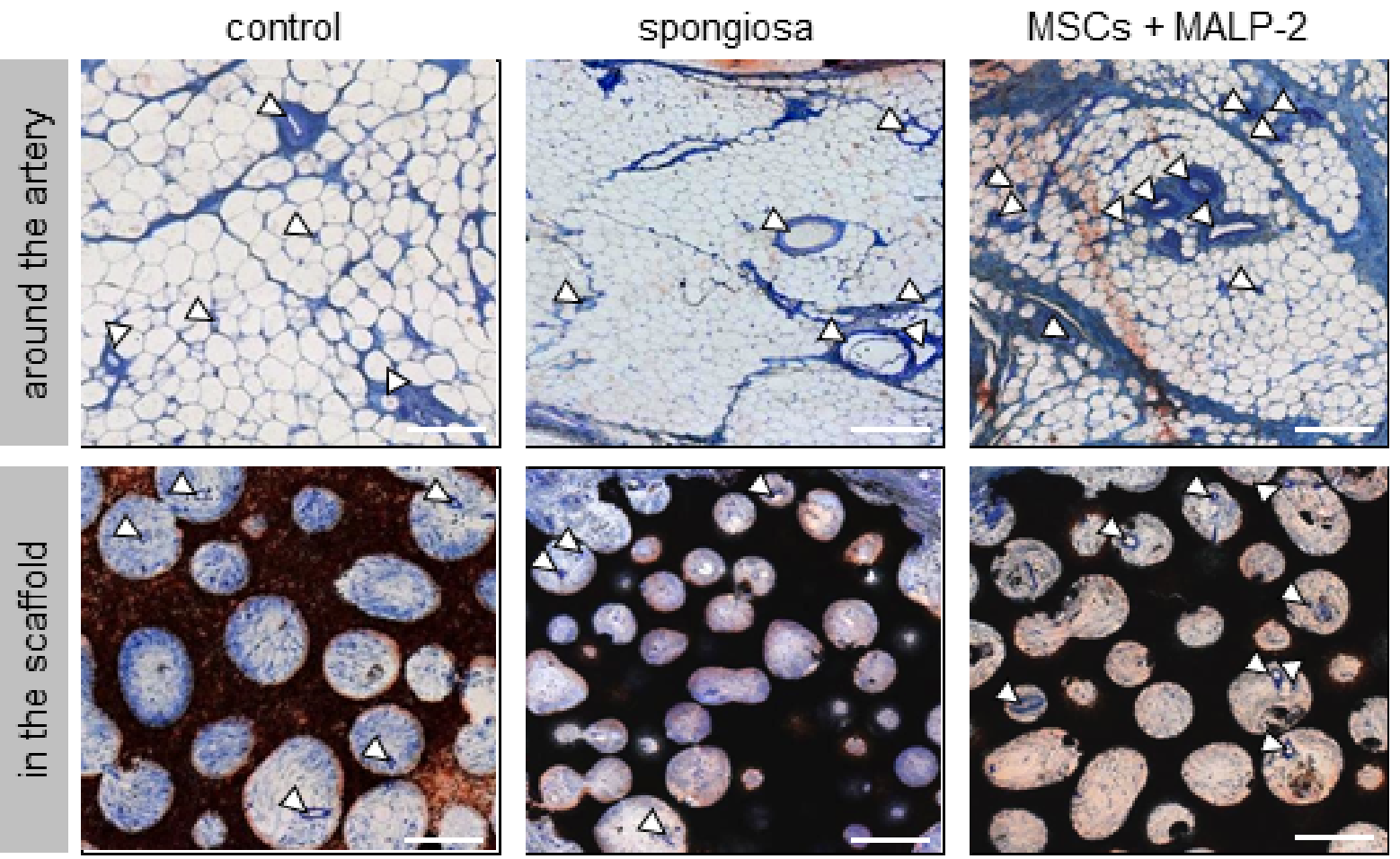

B

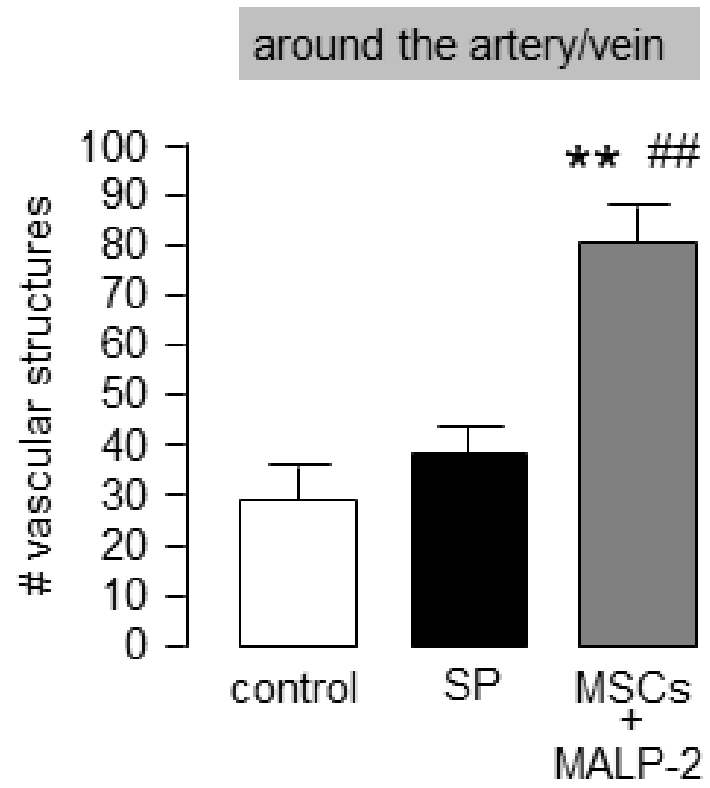

in the scaffold

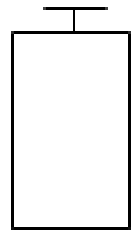

control

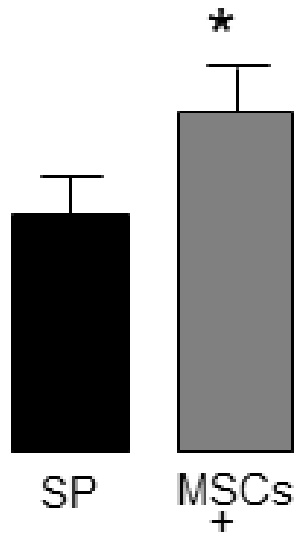

MALP-2

Fig. 6. Implantation of MALP-2-treated autologous MSCs enhanced vessel density in the latissimus dorsi muscle of sheep. $\beta$-TCP cylinders were loaded with autologous blood (control), spongiosa (SP) and MALP-2 treated autologous MSCs and implanted into the left M. latissimus dorsi of sheep for 6 months. (A) Pictures represent alizarine-methylene stained sections of the explanted grafts around the artery (upper row) and in the scaffold (lower row). White arrowheads indicate vascular structures (capillaries and arterioles). Scale bar $=200 \mu \mathrm{m}$. (B) Vascular structures were quantified.

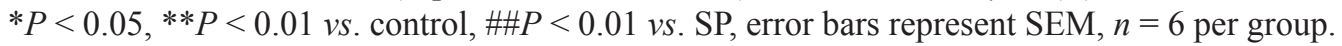

from dermal wound healing to anti-tumour treatment (Rharbaoui et al., 2002; Deiters et al., 2003; Schneider et al., 2004; Schmidt et al., 2007). Of note, we uncovered a tissue regenerative capacity of MALP-2. In this regard, we reported that MALP-2 induced angiogenesis in a TLR2/6- dependent manner. The angiogenic process is particularly driven by the release of the growth factor GM-CSF from endothelial cells and monocytes and may represent an endogenous mechanism to restore capillaries in infected tissues in order to recruit immune cells for pathogen 
defence (Grote et al., 2010). Recently, we demonstrated that MALP-2 could be even used in a therapeutic manner to restore an endothelial damage after experimental vascular injury (Grote et al., 2013).

Thus, the beneficial effect of MALP-2 on vascular regeneration is already well documented in mice. In this regard, experiments in larger animals are required for a potential clinical use of MALP-2 in the future. In the present study, we went one step further and used human MSCs for in vitro studies and a complex sheep model for in vivo studies on therapeutic angiogenesis. TLR expression in MSCs was already reported, with implications to various cellular functions such as migration (Pevsner-Fischer et al., 2007; DelaRosa and Lombardo, 2010). Accordingly, we were able to demonstrate TLR2 and TLR6 expression in cultured human MSCs of early passages, which were used for subsequent experiments. We observed that MALP-2 is a direct migratory but not mitogenic stimulus for human MSCs. In contrast to our data, Lei et al. (Lei et al., 2011) reported that TLR2 ligation suppressed MSC migration. However, Lei and colleagues used the triacetylated artificial Pam ${ }_{3}$ Cys which signals differently from MALP-2, via a heterodimer of TLR2 with TLR1 (Lei et al., 2011). Even though MSCs seem to be able to differentiate into endothelial cells under certain conditions (Oswald et al., 2004), their reported angiogenic properties are widely regarded as paracrine effects (Kasper et al., 2007; Wang et al., 2011). In line with this concept, we found that supernatants from cultured human MSC enhanced migration and proliferation of endothelial cells. We could not observe any effects on tube formation of endothelial cells with supernatants from human MSCs in our experiments. However, compared to these untreated supernatants, supernatants from MALP-2 pre-treated human MSCs significantly increased migration, proliferation and tube formation of endothelial cells, which are known as important cellular processes during angiogenesis. In this regard, MALP-2 has been shown to induce several cytokines and growth factors such as the major angiogenic factor VEGF from monocytes, which act as paracrine factors in angiogenesis and wound healing (Deiters et al., 2004). We recently identified GM-CSF, which is secreted by endothelial cells in response to MALP2 as the major autocrine factor for MALP-2-induced angiogenesis (Grote et al., 2010). Similarly, we now found that MALP-2 induced the release of different factors with angiogenic properties from human MSCs including VEGF and GM-CSF. Taken together, we demonstrated that preconditioning of human MSCs with MALP-2 enhanced angiogenesis in vitro in a paracrine manner. This concept seems to be applicable to angiogenic therapy in vivo, since MALP-2 preconditioned MSCs enhanced vascular density in a sheep model of tissue engineering of bone. TLR activation in MSCs may represent a novel therapeutic approach, since Mastri et al. recently described that TLR3 activation augmented the release of trophic factors by MSCs and enhanced their therapeutic potency (Mastri et al., 2012).

From our point of view, there are two different approaches to use the scientific gain of knowledge of our study for therapeutic angiogenesis in tissue engineering of bone: (1) a direct application of MALP-2, e.g., incorporated in or coated onto a scaffold matrix of an in vitro or in vivo engineered construct; or (2) an indirect application of MALP-2, e.g., in a cell transplantation approach with a defined MALP-2 treatment of the cells before or at the time of transplantation. We here started to investigate the latter approach by transplantation of MALP-2 treated human MSCs. In this regard, our in vivo study represents a pilot study to evaluate the potential of MALP-2-treated MSCs in an experimental model of tissue engineering. Further animal experiments are needed to compare different experimental settings and elucidate the optimal regime for a potential future clinical application of MALP-2 in therapeutic angiogenesis.

\section{Conclusions}

In summary, we here provide evidence that MALP-2 directly enhances the migration of human MSCs. In addition, MALP-2 promotes angiogenic processes such as migration, proliferation and tube formation of endothelial cells in a paracrine manner. Finally, we demonstrate that this concept is therapeutically applicable in an experimental sheep model of tissue engineering of bone. We detect significantly more capillaries and vessels after transplantation of constructs containing MALP-2 treated autologous MSCs. Related tissue-engineering concepts may be used for therapeutic angiogenesis in different regenerative applications.

\section{Acknowledgements}

The authors would like to thank Roland Meister, Silke Pretzer and Mirja Sirisko for excellent technical assistance and Prof. Peter Mühlradt for support in the handling of MALP-2.

\section{References}

Armstrong L, Lako M, Buckley N, Lappin TR, Murphy MJ, Nolta JA, Pittenger M, Stojkovic M (2012) Editorial: Our top 10 developments in stem cell biology over the last 30 years. Stem Cells 30: 2-9.

Bancroft GN, Sikavitsas VI, van den Dolder J, Sheffield TL, Ambrose CG, Jansen JA, Mikos AG (2002) Fluid flow increases mineralized matrix deposition in $3 \mathrm{D}$ perfusion culture of marrow stromal osteoblasts in a dose-dependent manner. Proc Natl Acad Sci USA 99: 12600-12605.

Broese M, Toma I, Haasper C, Simon A, Petri M, Budde S, Wehmeier M, Krettek C, Jagodzinski M (2011) Seeding a human tendon matrix with bone marrow aspirates compared to previously isolated hBMSCs--an in vitro study. Technol Health Care 19: 469-479.

Brown J, Wang H, Hajishengallis GN, Martin M (2011) TLR-signaling networks: an integration of adaptor molecules, kinases, and cross-talk. J Dent Res 90: 417-427.

Crisostomo PR, Wang Y, Markel TA, Wang M, Lahm T, Meldrum DR (2008) Human mesenchymal stem cells 
stimulated by TNF-alpha, LPS, or hypoxia produce growth factors by an NF kappa B- but not JNK-dependent mechanism. Am J Physiol Cell Physiol 294: C675-682.

Cuiffo BG, Karnoub AE (2012) Mesenchymal stem cells in tumor development: Emerging roles and concepts. Cell Adh Migr 6: 220-230.

Deiters U, Gumenscheimer M, Galanos C, Muehlradt PF (2003) Toll-like receptor 2- and 6-mediated stimulation by macrophage-activating lipopeptide 2 induces lipopolysaccharide (LPS) cross tolerance in mice, which results in protection from tumor necrosis factor alpha but in only partial protection from lethal LPS doses. Infect Immun 71: 4456-4462.

Deiters U, Barsig J, Tawil B, Mühlradt PF (2004) The macrophage-activating lipopeptide-2 accelerates wound healing in diabetic mice. Exp Dermatol 13: 731-739.

DelaRosa O, Lombardo E (2010) Modulation of adult mesenchymal stem cells activity by toll-like receptors: implications on therapeutic potential. Mediators Inflamm 2010: 865601 .

Gómez-Barrena E, Rosset P, Müller I, Giordano R, Bunu C, Layrolle P, Konttinen YT, Luyten FP (2011) Bone regeneration: stem cell therapies and clinical studies in orthopaedics and traumatology. J Cell Mol Med 6: 12661286.

Grote K, Schuett H, Salguero G, Grothusen C, Jagielska J, Drexler H, Mühlradt PF, Schieffer B (2010) Toll-like receptor 2/6 stimulation promotes angiogenesis via GM$\mathrm{CSF}$ as a potential strategy for immune defense and tissue regeneration. Blood 115: 2543-2552.

Grote K, Sonnenschein K, Kapopara PR, Hillmer A, Grothusen C, Salguero G, Kotlarz D, Schuett H, Bavendiek U, Schieffer B (2013) Toll-like receptor 2/6 agonist macrophage-activating lipopeptide-2 promotes reendothelialization and unhibits neointima formation after vascular injury. Arterioscler Thromb Vasc Biol, in press.

Haasper C, Jagodzinski M, Drescher M, Meller R, Wehmeier M, Krettek C, Hesse E (2008) Cyclic strain induces FosB and initiates osteogenic differentiation of mesenchymal cells. Exp Toxicol Pathol 59: 355-363.

Hesse E, Kluge G, Atfi A, Correa D, Haasper C, Berding G, Shin HO, Viering J, Länger F, Vogt PM, Krettek C, Jagodzinski M (2010) Repair of a segmental long bone defect in human by implantation of a novel multiple disc graft. Bone 46: 1457-1463.

Jagodzinski M, Drescher M, Zeichen J, Hankemeier S, Krettek C, Bosch U, van Griensven M (2004) Effects of cyclic longitudinal mechanical strain and dexamethasone on osteogenic differentiation of human bone marrow stromal cells. Eur Cell Mater 7: 35-41.

Jagodzinski M, Breitbart A, Wehmeier M, Hesse E, Haasper C, Krettek C, Zeichen J, Hankemeier S (2008) Influence of perfusion and cyclic compression on proliferation and differentiation of bone marrow stromal cells in 3-dimensional culture. J Biomech 41: 1885-1891.

Kanczler JM, Oreffo RO (2008) Osteogenesis and angiogenesis: the potential for engineering bone. Eur Cell Mater 15: 100-114.

Kasper G, Dankert N, Tuischer J, Hoeft M, Gaber T, Glaeser JD, Zander D, Tschirschmann M, Thompson M, Matziolis G, Duda GN (2007) Mesenchymal stem cells regulate angiogenesis according to their mechanical environment. Stem Cells 25: 903-910.

Lei J, Wang Z, Hui D, Yu W, Zhou D, Xia W, Chen C, Zhang Q, Wang Z, Zhang Q, Xiang AP (2011) Ligation of TLR2 and TLR4 on murine bone marrow-derived mesenchymal stem cells triggers differential effects on their immunosuppressive activity. Cell Immunol 271: 147-156.

Macedo L, Pinhal-Enfield G, Alshits V, Elson G, Cronstein BN, Leibovich SJ (2007) Wound healing is impaired in MyD88-deficient mice: a role for MyD88 in the regulation of wound healing by adenosine A2A receptors. Am J Pathol 171: 1774-1788.

Mastri M, Shah Z, McLaughlin T, Greene CJ, Baum L, Suzuki G, Lee T (2012) Activation of Toll-like receptor 3 (TLR3) amplifies mesenchymal stem cell trophic factors and enhances therapeutic potency. Am J Physiol Cell Physiol 303: C1021-1033.

Medzhitov R, Preston-Hurlburt P, Janeway CA Jr (1997) A human homologue of the Drosophila Toll protein signals activation of adaptive immunity. Nature 388: 394397.

Muehlradt PF, Kiess M, Meyer H, Suessmuth R, Jung G (1997) Isolation, structure elucidation, and synthesis of a macrophage stimulatory lipopeptide from Mycoplasma fermentans acting at picomolar concentration. J Exp Med 185: 1951-1958.

Oswald J, Boxberger S, Jørgensen B, Feldmann S, Ehninger G, Bornhäuser M, Werner C (2004) Mesenchymal stem cells can be differentiated into endothelial cells in vitro. Stem Cells 22: 377-384.

Pevsner-Fischer M, Morad V, Cohen-Sfady M, RoussoNoori L, Zanin-Zhorov A, Cohen S, Cohen IR, Zipori D (2007) Toll-like receptors and their ligands control mesenchymal stem cell functions. Blood 109: 1422-1432.

Piec G, Mirkovitch J, Palacio S, Mühlradt PF, Felix R (1999) Effect of MALP-2, a lipopeptide from Mycoplasma fermentans, on bone resorption in vitro. Infect Immun 67: 6281-6285.

Pittenger MF, Mackay AM, Beck SC, Jaiswal RK, Douglas R, Mosca JD, Moorman MA, Simonetti DW, Craig S, Marshak DR (1999) Multilineage potential of adult human mesenchymal stem cells. Science 284: 143-147.

Rameshwar P (2012) Current thoughts on the therapeutic potential of stem cell. Methods Mol Biol 879: 3-26.

Rharbaoui F, Drabner B, Borsutzky S, Winckler U, Morr M, Ensoli B, Muehlradt PF, Guzmán CA (2002) The Mycoplasma-derived lipopeptide MALP-2 is a potent mucosal adjuvant. Eur J Immunol 32: 2857-2865.

Schmidt J, Welsch T, Jäger D, Mühlradt PF, Büchler MW, Märten A (2007) Intratumoural injection of the toll-like receptor-2/6 agonist 'macrophage-activating lipopeptide-2' in patients with pancreatic carcinoma: a phase I/II trial. Br J Cancer 97: 598-604.

Schneider C, Schmidt T, Ziske C, Tiemann K, Lee KM, Uhlinsky V, Behrens P, Sauerbruch T, Schmidt-Wolf IG, Mühlradt PF, Schmidt J, Märten A (2004) Tumour suppression induced by the macrophage activating lipopeptide MALP-2 in an ultrasound guided pancreatic carcinoma mouse model. Gut 53: 355-361. 
Seki E, Tsutsui H, Iimuro Y, Naka T, Son G, Akira S, Kishimoto T, Nakanishi K, Fujimoto J (2005) Contribution of Toll-like receptor/myeloid differentiation factor 88 signaling to murine liver regeneration. Hepatology 41: 443-450.

Taguchi T, Mitcham JL, Dower SK, Sims JE, Testa JR (1996) Chromosomal localization of TIL, a gene encoding a protein related to the Drosophila transmembrane receptor Toll, to human chromosome 4p14. Genomics 32: 486-488.

Takeda K, Kaisho T, Akira (2003) Toll-like receptors. Annu Rev Immunol 21: 335-376.

Takeuchi O, Kaufmann A, Grote K, Kawai T, Hoshino K, Morr M, Muehlradt PF, Akira S (2000) Cutting edge: preferentially the R-stereoisomer of the mycoplasmal lipopeptide macrophage-activating lipopeptide- 2 activates immune cells through a toll-like receptor 2- and MyD88dependent signaling pathway. J Immunol 164: 554-557.

Takeuchi O, Kawai T, Muehlradt PF, Morr M, Radolf JD, Zychlinsky A, Takeda K, Akira S (2001) Discrimination of bacterial lipoproteins by Toll-like receptor 6. Int Immunol 13: 933-940.

Vemuri MC, Chase LG, Rao MS (2011) Mesenchymal stem cell assays and applications. Methods Mol Biol 698: 3-8.

Wang J, Liao L, Tan J (2011) Mesenchymal-stem-cellbased experimental and clinical trials: current status and open questions. Expert Opin Biol Ther 11: 893-909.

Wu Y, Chen L, Scott PG, Tredget EE (2007) Mesenchymal stem cells enhance wound healing through differentiation and angiogenesis. Stem Cells 25: 26482659.
Yu L, Wang L, Chen S (2010) Endogenous toll-like receptor ligands and their biological significance. J Cell Mol Med 14: 2592-2603.

\section{Discussion with Reviewers}

J. Amedee: Cells were cultured in endothelial cell growth medium (EGM72; Lonza) supplemented with $2 \%$ FCS, growth factors (epidermal growth factor, vascular endothelial growth factor, fibroblast growth factor, insulinlike growth factor). Define the concentration of these growth factors.

Authors: Unfortunately, Lonza does not give detailed information on the concentration of these growth factors - neither on the datasheets nor on their homepage.

J. Amedee: The effect of CM + MALP-2 on cumulative tube length (Fig. 4D) is difficult to appreciate because the percentage of stimulation remains weak. However, data is more evident in Fig. 4F.

Authors: The effect of MALP-2 in Fig. 4F (aortic ring assay, endothelial tube outgrowth) is much more striking than in Fig. 4D (endothelial tube formation). However, these two assays evaluate distinct different angiogenic properties of endothelial cells. MALP-2 significantly promotes angiogenic effects in both assays. The first assay measures mainly sprouting and growth elongation whereas the second assay similarly measures branching. Since both are crucial for angiogenesis we think that also the somewhat weaker effect of MALP-2 in Fig. 4D is worthwhile mentioning. 